

\title{
Pembangunan Monolingual Word Alignment Pada Terjemahan Al-Quran Berbahasa Indonesia
}

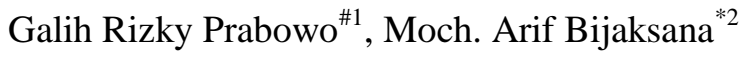 \\ \# Departemen Fakultas Informatika, Universitas Telkom \\ Jl. Telekomunikasi No. 01, Terusan Buah Batu, Sukapura, Dayeuhkolot, Sukapura, Dayeuhkolot, Bandung, Jawa Barat \\ 40257 \\ 'galihrizkypestudents.telkomuniversity.ac.id \\ ${ }^{2}$ arifbijaksana@telkomuniversity.ac.id
}

\begin{abstract}
Abstrak - Telah berabad-abad Al-Qur'an hadir di tengahtengah peradaban dan pergaulan umat manusia yang terdiri dari 6236 ayat. Untuk mengukur kesamaan semantik antar terjemahan ayat Al-Quran yang bertujuan untuk memahami lebih dalam terhadap makna yang terkait pada ayat Al-Quran dibutuhkan suatu metode salah satunya dengan monolingual word alignment. Monolingual alignment adalah metode penyejajaran kata yang mengidentifikasi kesamaan antar kata dalam pasangan kalimat yang ada. Selain penggunaan metode monolingual alignment dalam pengukuran kesamaan kata yang ada, dibutuhkan pula sebuah dataset yang di align yang berfungsi sebagai kumpulan dari objek yang isinya adalah hubungan semantik antar sets yang ada. Namun dataset monolingual word alignment untuk bahasa Indonesia berformat MSR masih sangat terbatas volumenya. Dalam penelitian ini, diaplikasikan beberapa fitur dalam metode monolingual alignment dalam pembangunan dataset monolingual word alignment bahasa Indonesia berformat MSR yaitu align identical words, align PFA dan align word sequences dengan menghasilkan nilai F1 $86.94 \%$. Untuk hasil F1 terbaik dihasilkan dari beberapa gabungan fitur alignment yaitu dengan fitur align identical words dan align PFA dengan hasil F1 sebesar $88.83 \%$.
\end{abstract}

\section{Kata kunci - Al-Quran, Monolingual Alignment, MSR}

Abstract-For centuries the Qur'an is present in the midst of civilization and human society consisting of 6236 verses. To measure the semantic similarity between the translations of AlQuran verses that aim to understand more deeply the meaning related to the verses of the Koran requires a method one of them with monolingual word alignment. Monolingual alignment is a word alignment method that identifies the similarity between words in existing pairs of sentences. In addition to the use of monolingual alignment methods in measuring the similarity of existing words, it also needs a dataset that serves as a collection of a document whose content is the semantic relationship between sets that exist. But the dataset monolingual word alignment for Indonesian in format MSR is still very limited in volume. In this research, some features in the method of monolingual alignment are applied in the development of the dataset monolingual word alignment Indonesian in format MSR, which is textit align identical words, align PFA and align word sequences by generating an F1 value of $86.94 \%$. For the best results $F 1$ is generated from some combination of alignment features with align identical words and align PFA with $F 1$ result of $88.83 \%$.

Keywords - Al-Quran, Monolingual Alignment, MSR

\section{PEndahuluan}

Telah berabad-abad Al-Qur'an hadir di tengah-tengah peradaban dan pergaulan umat manusia. Al-Qur'an terdiri dari 6236 ayat, pada 6236 ayat ini terdapat ayat-ayat yang memiliki makna yang sama dan saling berkaitan, maka dari itu diperlukan pengkajian lebih dalam untuk dapat memahami makna yang terkait pada ayat Al-Qur'an tersebut. Salah satu metode yang dapat dilakukan untuk mengukur kesamaan atau similarity dari sepasang antar kalimat secara efektif adalah dengan cara alignment atau penjajaran kata. Alignment merupakan salah satu metode yang sederhana, cepat serta mempunyai akurasi yang tinggi sesuai dengan tujuan pembuatan sistemnya. Untuk mengukur kesamaan pada kalimat terjemahan yang berbahasa sama, metode monolingual alignment sangat efektif karena dapat menjajarkan kata dalam bahasa yang sama.

Dalam sebuah penelitian mencari sebuah kesamaan semantik antar kalimat berbahasa Indonesia yang menggunakan metode monolingual alignment yaitu metode untuk mengukur kemiripan dari sepasang kalimat dalam bahasa yang sama, dibutuhkan sebuah dataset monolingual alignment yang berfungsi sebagai kumpulan dari objek yang isinya adalah hubungan semantik antar sets yang ada. Saat ini terdapat korpus monolingual alignment dari penelitian MSR RTE 2007 dalam Bahasa Inggris [1]. Namun korpus monolingual word alignment antar Bahasa Indonesia khususnya untuk terjemahan AlQuran masih sangat terbatas volumenya.

Pada penelitian ini, dibuat sebuah sistem yang dapat membangun data latih dengan metode monolingual alignment terjemahan Al-Quran berbahasa Indonesia dengan input berupa pasangan kata terjemahan yang belum di align dan output berupa pasangan kata 
terjemahan yang telah di align yang bertujuan untuk mempermudah proses penelitian mencari kesamaan semantik antar kalimat pada terjemahan Al-Quran berbahasa Indonesia tanpa harus menggunakan korpus terjemahan dari bahasa Inggris.

\section{Metodologi}

Sistem yang akan dibangun pada penelitian ini bertujuan untuk membangun sebuah data latih monolingual word alignment pada terjemahan Al-Quran berbahasa Indonesia. Gambaran umum sistem yang akan dibangun ditunjukan pada Gambar. 1.



Gambar. 1 Gambaran umum sistem

\section{A. Pengumpulan Data}

Data yang digunakan dalam pesnelitian ini adalah data yang dibuat secara manual mengikuti format data MSR yang diambil dari pasangan terjemahan Al-Quran Bahasa Indonesia Al-Ustadz Muhammad Thalib sebanyak 288 ayat dan terjemahan Al-Quran Al-Muyassar sebanyak 288 ayat yang meliputi surat Al-Maarij, Al-Mursalah, AlQiyamah, Ar-Rahman dan Al-Waqiah. Data pasangan ayat tersebut disimpan dalam format .txt agar data lebih fleksibel dalam proses pengolahannya.

\section{B. Preprocessing}

Pada tahap preprocessing data yang ada sebelumnya dilakukan proses modifikasi agar dapat digunakan dalam sistem yang akan dibangun. Data yang digunakan berupa data terjemahan Al-Quran berbahasa Indonesia dengan format MSR seperti contoh berikut ini:

sentence pair 2

Yang telah mengajarkan Al-Quran .

$\operatorname{NULL}(/ /$ ) Tuhan ( / / ) yang ( $1 / /$ ) mengajarkan ( $3 /$ / )

Al-Quran ( $4 / /) \operatorname{kepada}(/ /) \operatorname{Muhammad}(/ /)$. (5//)
Tahap preprocessing dalam penelitian ini meliputi 3 (tiga) tahap yaitu pembersihan data, tokenization dan stemming.

1) Pembersihan data: Kalimat kedua dalam dataset berformat MSR merupakan gold standard yang perlu dilakukan proses pembersihan dan pemisahan data yang nantinya hanya akan diambil kata nya saja untuk proses yang dilakukan sistem. Diperlukan sebuah regular expression untuk melakukan pemisahan kata dengan karakter ( / / ) serta atribut 'NULL' yang ada dalam kalimat kedua dalam data berformat MSR. Hasil dari pemisahan kata dengan atribut ( / / ) dan atribut 'NULL' menggunakan regular expression seperti contoh berikut ini:

Yang telah mengajarkan Al-Quran .

Tuhan yang mengajarkan Al-Quran kepada Muhammad .

2) Tokenization: Setelah data terpisah dengan atribut yang ada sebelumnya kemudian dilakukan proses tokenization atau pemisahan antar kata dan dilakukan proses lower case atau merubah semua kata menjadi huruf kecil agar memudahkan sistem melakukan alignment dengan bantuan library NLTK sehingga menghasilkan output dalam bentuk list seperti contoh berikut ini:

'yang', 'telah', 'mengajarkan', 'al-quran', '.'

'tuhan', 'yang', 'mengajarkan', 'al-quran', 'kepada', 'muhammad', '.'

3) Stemming: Setelah dilakukan proses tokenization, preprocessing yang dilakukan selanjutnya adalah proses stemming atau memotong imbuhan kata dalam kalimat menjadi kata dasar dengan bantuan library stemming bahasa Indonesia yaitu Sastrawi Stemmer dan menghasilkan output seperti berikut ini:

'yang', 'telah', 'ajar', 'al-quran', '.'

'tuhan', 'yang', 'ajar', 'al-quran', 'kepada', 'muhammad', '.'

\section{Kamus Data Parafrase Al-Quran (PFA)}

Data Pasangan Frase Al-Quran merupakan data yang isinya memuat tentang pasangan kata atau frase yang mempunyai kemiripan makna khususnya pada terjemahan ayat Al-Quran. Data PFA digunakan sebagai sebuah databasel kamus untuk implementasi salah satu fitur dalam metode word alignment yaitu align PPDB. Dikarenakan PPDB dalam bahasa Indonesia belum tersedia, khususnya untuk terjemahan Al-Quran berbahasa Indonesia digunakan lah database PFA sebagai pengganti PPDB. Saat ini, telah dibangun seratus data PFA dengan cara reverse engineering yang berisi pasangan frase atau kata yang mempunyai makna yang sama yang didapat dari perbandingan ayat dari kedua versi terjemahan Al-Quran yang berbeda. Untuk menentukan kata yang teridentifikasi sebagai parafrase, dilakukan pengecekan secara manual terhadap kamus KBBI Bahasa Indonesia. Format data dari PFA terjemahan Al-Quran berbahasa Indonesia mengikuti format PPDB bahasa Inggris. Adapun contoh dari kamus PFA seperti pada Tabel. I. 
TABEL I

CONTOH KAMUS PFA (PARAFRASE AL-QURAN)

\begin{tabular}{|l|l|}
\hline aku & saya \\
\hline aku & kami \\
\hline ajakan-ajakan & ajakan \\
\hline alamin & semesta alam \\
\hline allah & tuhan \\
\hline amat & sekali \\
\hline amat & sangat \\
\hline
\end{tabular}

\section{Implementasi Fitur Alignment}

Dalam penelitian ini, digunakan sistem monolingual alignment untuk menguji performansi dari data terjemahan Al-Quran berbahasa Indonesia dengan format MSR. Fitur alignment yang digunakan dalam penelitian ini meliputi align identical words, align PFA dan align word sequences. Berikut adalah contoh implementasi dari algoritma alignment serta alur alignment yang ditunjukkan pada Gambar. 2 dan Gambar. 3.

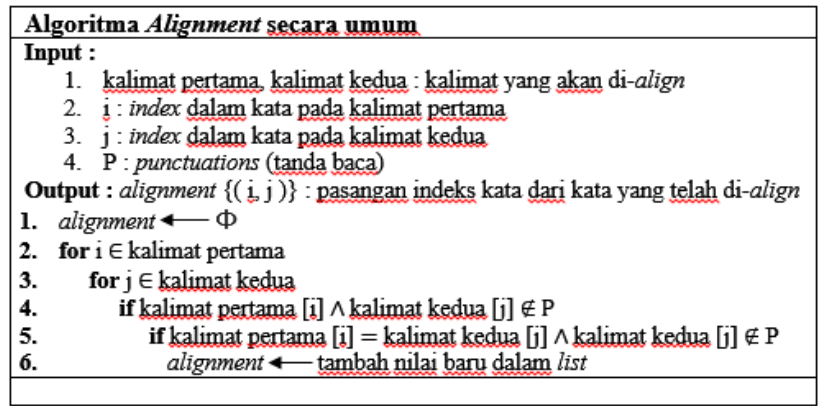

Gambar. 2 Algoritma alignment

1) Align Identical Words: Hal yang paling sederhana dalam mengetahui kesamaan antar kata dalam pasangan kalimat yaitu dengan melihat kemunculan kata yang identik dalam kedua pasangan tersebut. Ilustrasi dari penggunaan fitur ini ada pada Gambar. 4.

2) Align PFA: Dalam identifikasi kata-kata yang memiliki makna yang sama selain dengan melihat kesamaan katanya, cara lain yang bisa dilakukan adalah dengan cara mengidentifikasi kesamaan makna nya menggunakan kamus / database. Kamus atau database yang digunakan dalam penelitian ini adalah PPDB. Namun kamus PPDB untuk Bahasa Indonesia khusus nya terjemahan Al-Quran belum tersedia. Oleh karena itu dalam penelitian ini digunakan kamus PFA (Parafrase AlQuran) yang dibuat manual oleh penulis. Apabila kata dalam kalimat pertama dan kedua termasuk atau terdaftar dalam database, maka kata tersebut dikategorikan align dengan fitur align PFA seperti contoh pada Gambar. 5.



Gambar. 3 Implementasi Fitur Alignment

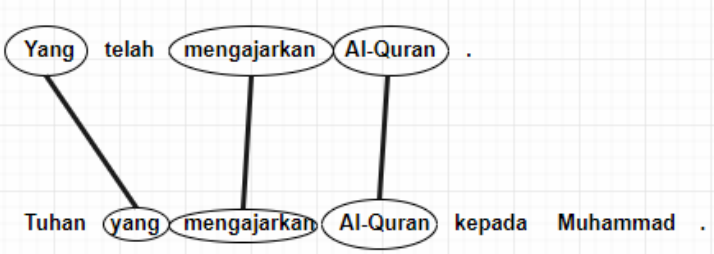

Gambar. 4 Contoh Align Identical Words



Dalam contoh pasangan kalimat diatas, tiap kata dalam pasangan kalimat akan diperiksa kedalam database PFA. Jika ada maka kata tersebut akan di align. Kata sombong dan congkak terdaftar dalam database maka kata tersebut align.

3) Align Word Sequence: Fitur align word sequence melakukan pengecekan terhadap jumlah keterurutan dari pasangan kalimat minimal dua kata yang mempunyai urutan kata yang sama. Contoh dalam Gambar. 6. 


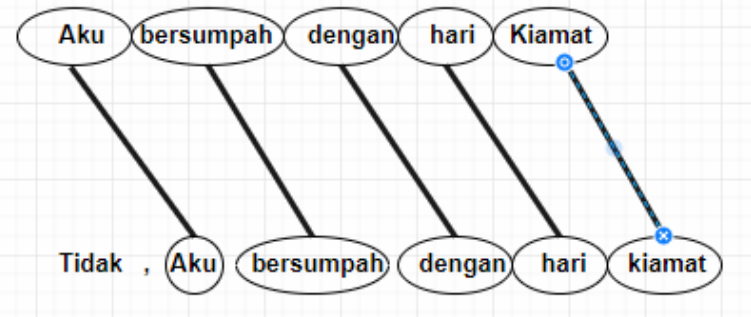

Gambar. 6 Contoh Align Word Sequences

\section{E. Evaluasi Hasil Alignment}

Setelah semua dataset telah diidentifikasi menggunakan semua fitur alignment selanjutnya dilakukan evaluasi menggunakan evaluasi intrinsik yang melakukan perbandingan antara hasil alignment dengan gold standard yang ada dalam dataset. Evaluasi intrisik juga mengukur F-measure yang meliputi pengukuran dari precision, recall dan F1 Score. Contoh data yang akan dilakukan proses evaluasi adalah sebagai berikut:

sentence pair 2

Yang telah mengajarkan Al-Quran .

$\operatorname{NULL}(/ /)$ Tuhan ( / / ) yang ( $1 /$ / ) mengajarkan ( 3 / / ) Al-Quran (4//) kepada (//) Muhammad (//). (5//)

Kalimat input diatas dibaca oleh sistem dan dilakukan preprocessing yaitu tokenization dan stemming sehingga menjadi:

Kalimat pertama : ['yang', 'telah', 'ajar', 'al-quran', "]

Kalimat kedua : ['tuhan', 'yang', 'ajar', 'al-quran', 'kepada', 'muhammad', "]

Setelah dilakukan proses preprocessing, data di atas dilakukan identifikasi oleh fitur alignment yaitu align identical words, align PFA dan align word sequences. Ditampilkan dalam bentuk list sebagai berikut Identical Words : [[2, 1], [3, 3], [4, 4], [7, 5]]

Identical from PPDB : []

Word Sequence : [[3, 3], [4, 4]]

Indeks nomor sebelah kiri yaitu indeks dari kata pada kalimat kedua, sedangkan indeks nomor sebelah kanan yaitu indeks dari kata pada kalimat pertama. Kalimat pertama bertindak sebagai sistem dan kalimat kedua bertindak sebagai gold standard. Gold standard dari kalimat input yang telah diproses oleh sistem adalah sebagai berikut:

Gold Annotation: [['tuhan', '( / / )'], ['yang', '( 1 / / )'], ['ajar', '( 3 / / )'], ['al-quran', '( 4 / / )'], ['kepada', '( / / )'], ['muhammad', '( / / )'], [", '( 5 / /)']]

Setelah gold standard dibandingkan dengan prediksi sistem, didapatkan hasil $F$-Measure yang meliputi pengukuran precision, recall dan F1 Score.

Jumlah Benar 4

Jumlah Sistem 4

jumlah Gold Annotation 4

precision 1.0 recall 1.0

F1 1.0

\section{F. Pengumpulan Pasangan Ayat Terjemahan yang sudah} di-Align

Pada tahap pengumpulan pasangan ayat terjemahan yang telah di align, semua dataset yang telah diuji dan dievaluasi oleh program berupa pengukuran dari skor precision, recall dan $F 1$ score dari tiap masing masing pasangan ayat terjemahan Al-Quran bahasa Indonesia yang telah di align kemudian dilakukan proses output dan disimpan dalam bentuk file berformat .txt. Hasil dari pengumpulan kalimat pasangan terjemahan ayat yang telah di align oleh sistem dan gold standard ini adalah sebuah data latih monolingual word alignment. Contoh hasil pengumpulan kalimat terjemahan ayat yang telah dilakukan proses aligning oleh sistem dan gold standard dan di visualisasikan dalam bentuk gambar agar lebih mudah dalam proses pembacaan nya adalah pada Gambar. 7.



Gambar. 7 Contoh Visualisasi Alignment

\section{G. Pembangunan Parafrase Secara Otomatis}

Setelah dilakukan proses pengumpulan pasangan kalimat yang telah diuji serta di-align oleh sistem dan anotasi manusia/ manual, sebagai tambahan, sistem akan membangun sebuah parafrase secara otomatis hasil dari prediksi alignment atau pensejajaran kata yang dilakukan oleh sistem. Dalam membangun himpunan parafrase secara otomatis, hasil alignment yang telah dihasilkan sebelumnya oleh sistem dilakukan pengecekan apakah dari hasil alignment oleh sistem antara kalimat pertama dan kalimat kedua terdapat jarak atau gap. Jika diantara kalimat pertama dan kalimat kedua tersebut terdapat gap, maka gap tersebut yang berada pada kedua pasangan kalimat tersebut teridentifikasi sebagai parafrasa. Contoh nya adalah sebagai pada Gambar. 8 .

Pada contoh gambar 8 , pada kalimat pertama yaitu kata dari dan pada kalimat kedua kata dari dengan kata api dalam pasangan kalimat pertama dan kata api dalam pasangan kalimat kedua terdapat gap atau jarak antar alignment oleh prediksi sistem tersebut. Maka oleh sistem, kedua kata tersebut yaitu kata nyala dalam kalimat pertama dan kata jilatan dalam kalimat kedua teridentifikasi sebagai parafrase. Untuk pengukuran 
akurasi serta evaluasi $f$-measure akan dijelaskan lebih detail pada Bab Hasil dan Pembahasan.

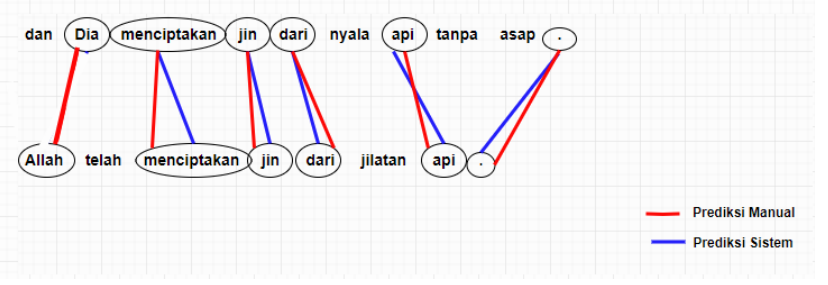

Gambar. 8 Contoh Pasangan Ayat yang Teridentifikasi Parafrase

\section{HASIL DAN PEMBAHASAN}

\section{A. Dataset}

Data yang digunakan dalam penelitian ini adalah datayang dibuat secara manual mengikuti format data MSR yang diambil dari pasangan terjemahan Al-Quran Bahasa Indonesia Al-Ustadz Muhammad Thalib sebanyak 288 ayat dan terjemahan Al-Quran Al-Muyassar sebanyak 288 ayat yang meliputi surat Al-Maarij, Al-Mursalah, Al Qiyamah, Ar-Rahman dan Al-Waqiah. Data pasangan ayat tersebut disimpan dalam format txt agar data lebih fleksibel dalam proses pengolahannya. Dalam format data yang berbentuk MSR, terdapat anotasi sure dan possible. Dalam penelitian ini, hanya digunakan anotasi sure dalam dataset terjemahan dengan format MSR yang bertujuan untuk memudahkan proses alignment sesuai yang dikemukakan pada penelitian Mac Cartney et.al[3]. Berikut adalah contoh dataset yang digunakan dalam penelitian ini

sentence pair 79

Aku bersumpah dengan hari Kiamat .

$\operatorname{NULL}(/ /) \operatorname{Tidak}(/ /),(/ /)$ Aku ( $1 / /)$ bersumpah ( $2 / /$ ) dengan (3//) hari (4//) kiamat (5//). (6//)

\section{B. Evaluation Metric}

Pada penelitian ini, hasil alignment pada dataset terjemahan Al-Quran berbahasa Indonesia berformat MSR diuji menggunakan evaluasi intrinsik dengan mengukur precision, recall dan F1 Score. Dalam data berformat MSR, terdapat 2 anotasi yaitu sure dan possible [1]. Anotasi sure adalah anotasi yang menjelaskan bahwa kata dalam kalimat kedua seharusnya align dengan indeks kata dalam kalimat pertama yang ditandai dengan angka mutlak dalam proses aligningnya sedangkan dalam anotasi possible menjelaskan bahwa kata dalam kalimat kedua yang menurut anotator bisa align dengan kata dalam kata pertama. Ditandai dengan huruf $\mathrm{p}$ sebelum indeks kata yang akan di align dalam kalimat pertama. Dalam mengevaluasi dataset MSR, digunakan F-Measure yang terdiri dari rumus precision, recall dan F1 Score pada persamaan berikut ini:

$$
\text { Precision }=\frac{\text { jumlahbenar }}{\text { jumlah prediksi sistem }}
$$

$$
\begin{gathered}
\text { Recall }=\frac{\text { jumlahbenar }}{\text { jumlah gold standard }} \\
F 1=\frac{2(\text { Precision } * \text { Recall) }}{\text { Precision }+ \text { Recall }}
\end{gathered}
$$

\section{Hasil Pengujian}

Berdasarkan hasil pengujian yang dilakukan pada penelitian ini menggunakan fitur align identical words, align PFA dan align word sequences didapat hasil yang akan dijelaskan pada Tabel 2.

TABEL II

HASIL PENGUJIAN

\begin{tabular}{|c|c|c|c|}
\hline System & Precision & Recall & F1 \\
\hline $\begin{array}{c}\text { This Work (Best } \\
\text { Feature) }\end{array}$ & $90.16 \%$ & $90.52 \%$ & $88.83 \%$ \\
\hline $\begin{array}{c}\text { This Work (Full } \\
\text { Feature) }\end{array}$ & $85.98 \%$ & $91.03 \%$ & $86.94 \%$ \\
\hline Batas Atas & $98.75 \%$ & $90.53 \%$ & $93.67 \%$ \\
\hline Batas Bawah & $22.47 \%$ & $24.16 \%$ & $22.62 \%$ \\
\hline
\end{tabular}

*Best Feature : Align Identical Words + Align PFA

Dalam penelitian ini, sistem yang dibangun menghasilkan akurasi terbaik sebesar $88.83 \%$ dengan menggunakan fitur alignment align identical words dan align PFA. Untuk mengetahui seberapa baik sistem yang dibagun dalam penelitian ini, digunakan perbandingan sistem menggunakan batas atas dan batas bawah. Hal ini dikarenakan tidak terdapatnya penelitian terkait pada data yang sama yaitu pasangan terjemahan Al-Quran berformat MSR dalam bahasa Indonesia. Batas atas adalah pengujian yang hasilnya didapat dari musyawarah/anotasi antar manusia tanpa diuji oleh sistem sedangkan untuk batas bawah adalah pengujian yang hasilnya didapat dari hasil random atau acak dari hasil alignment tiap fitur yang diimplementasikan dalam sistem. Beberapa faktor yang mempengaruhi hasil performansi dari F1 skor dapat naik atau turun dipengaruhi oleh faktor hasil yang berbeda dengan gold standard dari fitur alignment yang digunakan dalam penelitian ini. Contohnya adalah ada beberapa kata dalam pasangan kata yang pertama dan kedua yang menurut program atau sistem secara makna sama tetapi setelah dibandingkan dengan gold standard kata dalam kedua pasangan tersebut tidak sama/tidak align. Analisis dan perbandingan hasil performansi tiap fitur yang digunakan dalam penelitian ini akan dijelaskan dalam Tabel 3.

TABEL III

ANALISIS HASIL DALAM PENGGUNAAN FITUR ALIGNMENT

\begin{tabular}{|c|c|c|c|}
\hline System & Precision & Recall & F1 \\
\hline $\begin{array}{c}\text { This Work (Full } \\
\text { Feature) }\end{array}$ & $85.98 \%$ & $91.03 \%$ & $86.94 \%$ \\
\hline (-) Identical Words & $74.43 \%$ & $54.14 \%$ & $60.78 \%$ \\
\hline (-) Align PFA & $87.49 \%$ & $89.20 \%$ & $86.81 \%$ \\
\hline $\begin{array}{c}\text { (-) Align Word } \\
\text { Sequence }\end{array}$ & $90.16 \%$ & $90.52 \%$ & $88.83 \%$ \\
\hline
\end{tabular}

D. Analisis Penggunaan Fitur Align Identical Words 
TABEL IV

ANALISIS PENGGUNAAN FITUR IDENTICAL WORDS

\begin{tabular}{|c|c|c|c|}
\hline System & Precision & Recall & F1 \\
\hline Full Feature & $85.98 \%$ & $91.03 \%$ & $86.94 \%$ \\
\hline (-) Identical Words & $74.43 \%$ & $54.14 \%$ & $60.78 \%$ \\
\hline
\end{tabular}

Fitur align identical word membandingkan antara dua pasangan kata yang memiliki kesamaan kata yang sama. Fitur ini adalah fitur yang paling dasar dalam metode monolingual alignment. Perbandingan hasil full feature dan tanpa fitur identical words mendapatkan hasil precision dan recall yang menurun yang bisa dilihat pada Tabel 3. Jika tanpa fitur identical words nilai precision turun sebesar $11.55 \%$ dan turunnya recall secara drastis sebesar $36.89 \%$. Hal ini menunjukan bahwa fitur identical word sangat berpengaruh dalam proses alignment antara dua pasangan kata. Hasil recall yang naik secara drastis jika menggunakan fitur identical words ini dikarenakan beberapa kata dari dataset yang ada dan diprediksi benar oleh sistem dengan gold standard, dikarenakan fitur ini hanya melakukan alignment terhadap kata yang sama tanpa melihat maknanya terhadap gold standard yang ada. Selain itu, kondisi yang menyebabkan precision turun adalah dimana suatu kata dalam pasangan kalimat menurut sistem seharusnya align tetapi menurut anotasi tidak align. Contoh kasusnya:

Kalimat pertama : Dia menciptakan manusia dari tanah kering seperti tembikar.

Kalimat kedua : NULL ( / / ) Allah ( $1 /$ / ) telah ( / / ) ciptakan ( / / ) manusia ( $3 / /$ ) dari ( $4 / /)$ tanah ( $5 / /)$ kering ( $6 /$ /) sekering (//) tembikar ( $7 / /) .(8 / /)$

Berdasarkan prediksi sistem, kata ciptakan pada kalimat kedua akan align dengan kata menciptakan pada kalimat pertama, namun menurut gold annotation kata tersebut tidak align. Hal inilah yang menyebabkan hasil precision menurun. Untuk perbandingan hasil skor $\mathrm{F} 1$, hasil terbaik didapat oleh pengujian dengan full feature dibandingkan dengan tanpa fitur identical words dengan selisih $26.16 \%$.

\section{E. Analisis Penggunaan Fitur Align PFA}

TABEL V

ANALISIS PENGGUNAAN FITUR ALIGN PFA

\begin{tabular}{|c|c|c|c|}
\hline System & Precision & Recall & F1 \\
\hline Full Feature & $85.98 \%$ & $91.03 \%$ & $86.94 \%$ \\
\hline (-) Align PFA & $87.49 \%$ & $89.20 \%$ & $86.81 \%$ \\
\hline
\end{tabular}

Fitur align PFA melakukan pengecekan terhadap kesamaan makna antara dua pasangan kata berdasarkan database PFA yang ada. Hasil yang didapat dari pengujian menggunakan full feature mendapatkan hasil yang lebih baik dibandingkan dengan tanpa fitur align $P F A$ yang ditunjukan dengan naik nya $F 1$ score sebesar $0.13 \%$ pada Tabel 4. Fitur ini memberikan pengaruh yang tidak terlalu signifikan dalam proses alignment karena kata dalam pasangan kalimat pertama dan kedua yang teridentifikasi oleh fitur ini sedikit. Meningkatnya skor pada recall ini karena kata dalam pasangan kata yang menurut gold annotation align atau sama dengan yang ada di dalam database PFA sehingga pasangan kata tersebut dianggap align/sejajar. Tetapi pada hasil yang dihasilkan oleh precision turun dikarenakan suatu kata dalam pasangan kalimat yang pertama menurut fitur/sistem dapat di align dengan pasangan kata yang kedua, tetapi menurut anotator tidak align. Contohnya:

Kalimat pertama : Tuhan ( yang memelihara) dua timur dan Tuhan (yang memelihara) dua barat.

Kalimat kedua : NULL ( / / ) Allah ( / / ) yang ( $3 / /$ ) menguasai $(4 / /)$ dua $(614 / /)$ tempat $(/ /)$ terbit $(/ /)$ matahari $(/ /)$ dan $(8 / /)$ dua $(614 / /)$ tempat $(/ /)$ terbenam (//) matahari $(/ /) .(16 / /)$

Berdasarkan prediksi sistem/fitur dari PFA, kata Allah pada kalimat kedua akan align dengan kata Tuhan pada kalimat pertama karena kedua kata dalam pasangan kalimat tersebut terdaftar dalam kamus PFA bahasa Indonesia yang dibangun secara manual. Tetapi menurut gold anotation kata Allah dan Tuhan tidak align. Hal ini yang menyebabkan hasil dari precision menurun.

\section{F. Analisis Penggunaan Fitur Align Word Sequences}

TABEL VI

ANALISIS PENGGUNAAN FITUR ALIGN WORD SEQUENCES

\begin{tabular}{|c|c|c|c|}
\hline System & Precision & Recall & F1 \\
\hline Full Feature & $85.98 \%$ & $91.03 \%$ & $86.94 \%$ \\
\hline (-) Align PFA & $87.49 \%$ & $89.20 \%$ & $86.81 \%$ \\
\hline
\end{tabular}

Fitur align word sequence melakukan pengecekan terhadap jumlah keterurutan dari pasangan kalimat minimal dua kata yang mempunyai urutan kata yang sama. Dalam pengujian ini, penggunaan tanpa fitur align word sequence tidak terlalu berpengaruh terhadap hasil alignment karena sebagian hasil dari fitur alignment ini sudah termasuk dalam hasil fitur dari identical words. Hal ini menyebabkan naiknya hasil dari recall sebesar $0.51 \%$ yang ditunjukkan pada Tabel 5 karena dipengaruhi oleh adanya beberapa pasangan kalimat pertama dan pasangan kalimat kedua yang menurut sistem dan gold annotation dianggap align dengan fitur ini. Dilihat dari Tabel 5, hasil F1 yang dihasilkan dengan tanpa fitur align word sequence menghasilkan skor F1 lebih baik sebesar $88.83 \%$ dibandingkan dengan full feature dengan hasil sebesar $86.94 \%$. Hal ini disebabkan oleh karakteristik pasangan ayat pada dataset yang lebih banyak mengandung kata identik dibandingkan dengan sekuen kata. Dikarenakan beberapa kata yang telah di align dengan fitur identical words belum tentu termasuk dalam kategori word sequence. 


\section{G. Analisis Hasil Pembangunan Parafrase Secara Otomatis}

TABEL VII

ANALISIS HASIL PEMBANGUNAN PARAFRASE SECARA OTOMATIS

\begin{tabular}{|c|c|c|c|c|}
\hline Precision & Recall & F1 & $\begin{array}{c}\text { Akurasi } \\
\text { Benar }\end{array}$ & $\begin{array}{c}\text { Akurasi } \\
\text { Salah }\end{array}$ \\
\hline $40.31 \%$ & $46.51 \%$ & $42.33 \%$ & $53.45 \%$ & $46.54 \%$ \\
\hline
\end{tabular}

Untuk proses pengukuran akurasi seberapa baik parafrase yang dihasilkan secara otomatis oleh sistem, dilakukan pengukuran secara manual dikarenakan sistem tidak bisa mengenali frase mana yang dianggap benar atau salah. Untuk pengukuran akurasi, digunakan validasi benar atau salah dan dihitung presentasenya. Jumlah paraphrase yang teridentifikasi oleh sistem sebanyak 275 kata. Jumlah benar yang di teridentifikasi adalah pasangan kata yang mempunyai makna yang mendekati sebanyak 147 kata sedangkan untuk jumlah yang salah yaitu pasangan kata yang tidak mempunyai makna yang mendekati sebanyak 128 kata. Jika dipresentasikan maka akurasi benar yaitu sebesar $53.45 \%$ dan akurasi salah sebesar $46.54 \%$ yang bisa dilihat pada Tabel 6 . Untuk perhitungan F-Measure menghasilkan nilai $42.33 \%$ yang melibatkan kombinasi antara precision dan recall menghasilkan hasil yang relatif rendah yaitu $40.31 \%$ untuk nilai precision dan $46.51 \%$ untuk nilai recall. Hasil $F$-measure ini didapat dari perbandingan prediksi sistem dengan gold standard sesuai dengan cara perhitungan dalam penelitian Xuchen et.al [12].

\section{KESIMPULAN}

Dalam penelitian ini telah dibangun sebuah sistem untuk membangun data latih monolingual word alignment pada terjemahan Al-Quran berbahasa Indonesia berupa data terjemahan yang telah dilakukan proses aligning oleh sistem dan gold standard dalam format data MSR dan di visualisasikan dalam bentuk gambar agar lebih mudah dalam proses pembacaannya. Dalam penelitian pembangunan monolingual word alignment pada terjemahan Al-Quran berbahasa Indonesia menghasilkan F1 Score terbaik didapat dari kombinasi dari 2 fitur alignment yang diimplementasikan yaitu align identical words dan align PFA dengan hasil F1 tertinggi sebesar $88.83 \%$

Penelitian lebih lanjut dapat dilakukan dengan menambahkan fitur contextual similarity seperti align named entity bahasa Indonesia khusus untuk data terjemahan Al-Quran agar tag yang dihasilkan sesuai dengan nama yang ada di Al-Quran dan fitur align content words yang meliputi fitur align dependency, align stopwords dan align neighbourhood. Memperbanyak dan menyempurnakan isi dari database PFA bahasa Indonesia serta menambahkan anotasi possible pada proses pembuatan gold standard berformat MSR merupakan hal yang dapat dilakukan dalam penelitian berikutnya.

\section{REFERENSI}

[1] C. Brockett. Aligning the rte 2006 corpus. MICROSOFT RESEARCH TECHNICAL REPORT MSR-TR-2007-77, 2004.

[2] I. Adiwijaya. Text mining dan knowledge discovery. Komunitas Data mining Indonesia Soft-omputing Indonesia, 2006.

[3] C. D. M. Bill MacCartney, Michel Galley. A phrase-based alignment model for natural language inference. Proceedings of the 2008 Conference on Empirical Methods in Natural Languag Processing pages $802-811,2008$.

[4] G. G. Adam Kilgarriff. Introduction to the special issue on the web as corpus. Computational Linguistics, 29:333-348.

[5] J. Euzenat. Semantic precision and recall for ontology alignment evaluation. In Proceedings of IJCAI-2007, 2007.

[6] L. T. C. O. R. M. Hannah Bechara, Rohit Gupta and J. van Genabith. Wolvesaar. Replicating the success of monolingual word alignment and neural embeddings for semantic textual similarity. In Proceedings of the 10th International Workshop on Semantic Evaluation (SemEval-2016), pages 634-639, 2016.

[7] T. I. Kasir. Tafsir Ibnu Kasir. Pustaka Al-Kautsar, 2011.

[8] T. S. Md Arafat Sultan, Steven Bethard. Back to basics for monolingual alignment: Exploitingword similarity and contextual evidence. Transactions of the Association for Computational Linguistics, pages 219-230, 2014.

[9] T. S. Md Arafat Sultan, Steven Bethard. Sentence similarity from word alignment. SemEval 2014, 2014.

[10] H. Suominen, S. Pyysalo, M. Hiissa, F. Ginter, S. Liu, D. Marghescu, T. Pahikkala, B. Back, H. Karsten, and T. Salakoski. Performance evaluation measures for text mining. 2:724-747, 2008

[11] A. W. Tony McEnery. Corpus linguistics: An introduction. Edinburgh University Press, 2001.

[12] X. Yao. Feature-driven question answering with natural language alignment. Dissertation submitted to Johns Hopkins University, 2008. 